\title{
PERCEPÇÃO DOS ESTUDANTES DO ENSINO MÉDIO SOBRE NOVAS METODOLOGIAS APLICADAS AO ENSINO DE ZOOLOGIA, COM ÊNFASE AOS PEIXES ORNAMENTAIS, EM UMA ESCOLA PÚBLICA EM FREI MARTINHO- PB
}

\author{
Maria Jildileide Silva de Almeida ${ }^{1}$, Ana Beatriz Nascimento de Macedo ${ }^{2}$, Marisa \\ de Oliveira Apolinário ${ }^{3}$ \\ ${ }^{1}$ Especialização em Educação com Foco em Ensino Aprendizagem, Centro de Educação e \\ Sáude, Universidade Federal de Campina Grande, Cuité-PB, Brasil. \\ ${ }^{2}$ Curso de Licenciatura em Ciências Biológicas, Unidade Acadêmica de Biologia e Química, \\ Centro de Educação e Saúde, Universidade Federal de Campina Grande, Cuité-PB, Brasil. \\ ${ }^{3}$ Prof ${ }^{a}$ Unidade Acadêmica de Biologia e Química, Centro de Educação e Saúde, Universidade \\ Federal de Campina Grande, Cuité-PB, Brasil.
}

Email para correspondência: biaah.macedo@hotmail.com

\begin{abstract}
Resumo
A forma compartimentalizada, sem contextualização e uso de metodologias inadequadas, nas quais o ensino de Zoologia se configura nos dias atuais, são alguns dos obstáculos que dificultam o ensino-aprendizagem. A presente pesquisa teve como objetivo desenvolver, aplicar e avaliar metodologias de ensino com educandos do Ensino Médio, na perspectiva de proporcionar uma melhor aprendizagem da Zoologia, com o foco no ensino de peixes ornamentais. O trabalho tem carater quali-quantitativo, através da aplicação de questionários específicos com discentes, onde para cada um desses momentos foi aplicado e avaliado um método para o ensino de Zoologia. Foi observado que $72 \%$ dos alunos responderam sobre as características que diferem os peixes ornamentais das demais espécies de peixes, sendo citados atributos como: cores, tamanhos e formas. Relacionado ao local de acesso à internet, a maioria dos alunos entrevistados (20) disseram acessar a internet em suas próprias casas, fazendo parte da rotina de muitos. Conclui-se que este trabalho gerou discussões que evidenciaram o êxito da aplicação dos métodos trabalhados, além de estimular a participação e aproximação entre os envolvidos, demonstrando ser uma ferramenta facilitadora do aprendizado de conceitos proporcionando a interatividade nas aulas tornando-as mais dinâmicas e prazerosas.
\end{abstract}

Palavras-chave: Ensino de Zoologia; Peixes Ornamentais; Modelos Didáticopedagógicos.

\begin{abstract}
The compartmentalized form, without contextualization and use of inadequate methodologies, in which the teaching of Zoology is configured in the present day, are some of the obstacles that impede teaching-learning. The present research
\end{abstract}


had as objective to develop, to apply and to evaluate methodologies of teaching with students of the High School, with the perspective of providing a better learning of the Zoology, with the focus in the teaching of ornamental fishes. The work has a qualitative-quantitative character, through the application of specific questionnaires with students, where for each of these moments a method for the teaching of Zoology was applied and evaluated. It was observed that $72 \%$ of the students answered on the characteristics that differ the ornamental fish of the other species of fish, being mentioned attributes like: colors, sizes and forms. Regarding internet access, most of the students interviewed (20) reported accessing the Internet in their own homes, being part of the routine of many. It is concluded that this work generated discussions that demonstrated the successful application of the methods worked, besides stimulating the participation and approximation among those involved, proving to be a facilitator of the learning of concepts, providing the interactivity in the classes making them more dynamic and pleasant.

Keywords: Zoology Education; Ornamental Fish; Didactic-Pedagogical models.

\section{INTRODUÇÃO}

De forma mecanizada, sem contextualização e com o uso de metodologias inadequadas e ultrapassadas, nas quais o ensino de Zoologia se encontra nos tempos atuais, são alguns dos desafios encontrados que dificultam o processo de ensino-aprendizagem. "A educação brasileira em suas limitações (e.g., lotação de salas aula, desvalorização do professor e defasada estrutura metodológica e didática) leva os docentes a questionamentos de "como" fazer e "com que" fazer educação, de maneira em que esta esteja ajustada aos Parâmetros Curriculares Nacionais e ao mercado de trabalho" (FOLLESDAL, 2000 apud HOLMESLAND, 2003).

As condições variadas numa escola exige uma relação à estrutura física, materiais didáticos, etc., como do educador, habilidades em projetar seus ensinamentos de forma que supere obstáculos que envolvem tanto as diferenças de cunho cultural, social como as de nível de aprendizagem, que fazem parte de uma comunidade escolar, isso tudo de acordo com as regras que ditam os Parâmetros Curriculares Nacionais - PCNs.

O ensino atualmente apresenta diversos desafios para os professores, tais como os alunos ficarem dispersos em sala de aula, ou com dificuldade para aprender com tal método, fazendo com que o educador busque maneiras de que o aluno fixe sua atenção e assim consiga aprender. Conforme Lima e Vasconcelos (2006) realçando que é um problema fixo e destinado ao profissional da educação que é tanto a teoria como a pratica, sendo assim, relacionando os assuntos abordados com o cotidiano do aluno, para que assim 
ele possa entender o significado e a importância de aprender determinando conteúdo.

Segundo Bizzo (2008), é de direito para todos os estudantes que o ensino de ciências e biologia proporcione oportunidades e competências para que possa se adquirir conhecimento e que os estudantes sintam-se entusiasmados em aprender algo desconhecido, aprendendo assim coisas novas. Para isso a escola tem total responsabilidade com os assuntos a serem trabalhados, pois eles serão a base dos alunos a desenvolverem o seu ponto de vista.

Para Lima e Vasconcelos (2006) o Modelo Didático Tradicional se define sendo aquele que transmite o conhecimento para o aluno, e ele recebe de forma mecanizada e toma isso como uma verdade inquestionável. Por isso a forma de ensino deve ser transformada no qual se insira novas didáticas para que o conteúdo não seja divagado de forma repetitiva e que os alunos não vejam a aprendizagem como algo que seja depositado neles de forma que não pode ser alterado.

A zoologia se encontra dentro do estudo científico da vida animal e esta incorporada ao ensino de Ciências e Biologia do ensino fundamental e médio, respectivamente. "O conteúdo geralmente é abordado no $7^{\circ}$ ano do ensino fundamental e no $2^{\circ}$ ano do ensino médio, sendo o estudo dessa temática importante para compreender as intervenções do homem na biodiversidade e para conhecer a importância dos animais na natureza" (SANTOS, 2010).

As pesquisas no campo da Zoologia nos remetem a pensar em como ela é posta nas escolas e em especial nas escolas públicas frente ao ensino de Ciências. "Os alunos do ensino Fundamental da rede pública na maioria das vezes se deparam com metodologias que nem sempre promovem a efetiva construção do conhecimento" (COSTA, 2014).

Outro ponto relevante é que, os alunos normalmente questionam os termos usados na biologia, pois os termos técnicos se tornam cansativos e até mesmo difíceis de aprender, fazendo com que o aluno perca o interesse em estar aprendendo ao conteúdo de zoologia por ter uma grande quantidade de palavras especificas. Utilizando a abordagem de apresentar outros recursos metodológicos como fotografias, filmes e jogos para os alunos, se torna uma ferramenta dinâmica e atrativa fazendo com que eles tenham um maior 
interesse nas aulas e no conteúdo, gerando uma maior participação e até mesmo podendo alcançar uma aprendizagem significativa.

Segundo Rocha (2014), o aquário como ferramenta de aprendizagem pode possibilitar aos alunos uma maior interação com o conteúdo estudado, dessa maneira a memorização de conteúdos debatidos e compreendidos pelo estudante é completamente diferente daquela que se reduz em decorar textos que posteriormente são cobrados em provas. A intenção é fazer com que o aluno na prática possa se divertir e aprender ao mesmo tempo, tornando a aprendizagem um ato prazeroso.

Uma das alternativas é a inclusão de modelos didático-pedagógicos que promovam uma aproximação entre professor e aluno e estes com o conteúdo ensinado. Sendo assim, segundo Pereira (1999), trabalhar com esses modelos pode ser uma ferramenta valiosa no ensino de ciências, já que às vezes o conteúdo pode ser difícil de ser interpretado, e com o incremento desse novo método de ensino, no qual o estudante vai construir a sua aprendizagem, e é esperado que ele aprendesse sobre um tema cientifico de forma mais prazerosa do que se fosse em uma aula tradicional.

O mundo atual tem como um dos seus objetivos ter transformações bruscas e rápidas proporcionadas pela internet e suas ferramentas. "A sociedade, ao se apropriar dessas tecnologias, sofreu interferência delas e se modificou principalmente no que diz respeito à forma como nos comunicamos e temos acesso às informações" (LUCY, 2012).

Tal modo evidência a carência de novos métodos que a escola tem que abordar para que essa esta possa suprir as necessidades da sociedade. Para que isso ocorra, autores como Serafim e Souza (2011), esclarecem que se faz necessário que o professor se aproprie das Novas Tecnologias Digitais da Educação e da Comunicação, a fim de utilizá-las a favor da educação, tornando-as práticas pedagógicas rotineiras em sala de aula.

Os PCNs orientam e apontam para instituições escolares, o uso das Tecnologias da Informação e Comunicação - TICs - como nova ferramenta metodológica, podendo ser utilizada pelos educadores para o aperfeiçoamento de suas aulas, como recurso didático que facilitaria o ensino dos conteúdos, além de tornar as aulas mais atrativas para os alunos, que em sua maioria, já 
estão familiarizados com o uso da internet, tornando o processo de ensino aprendizagem mais dinâmico.

Diante dessa realidade, este trabalho teve como objetivo buscar desenvolver, aplicar e avaliar metodologias de ensino com educandos do Ensino Médio em uma Escola da rede Estadual de ensino na Cidade de Frei Martinho - PB, na perspectiva de proporcionar uma melhor aprendizagem da zoologia, com o foco no ensino de peixes ornamentais.

\section{METODOLOGIA}

\section{1 Área de estudo}

A presente pesquisa foi desenvolvida na Escola Estadual de Ensino Médio Prefeito Aguitônio Dantas (Figura 1), escola da Rede Estadual de Ensino, situada na cidade de Frei Martinho - PB, com um total de 75 educandos, distribuídos entre os três ciclos do Ensino Médio, no período de agosto a novembro de 2017. Para a pesquisa todos os alunos que participaram estavam autorizados por pais ou responsáveis perante a assinatura do Termo de Consentimento Livre e Esclarecido (TCLE).

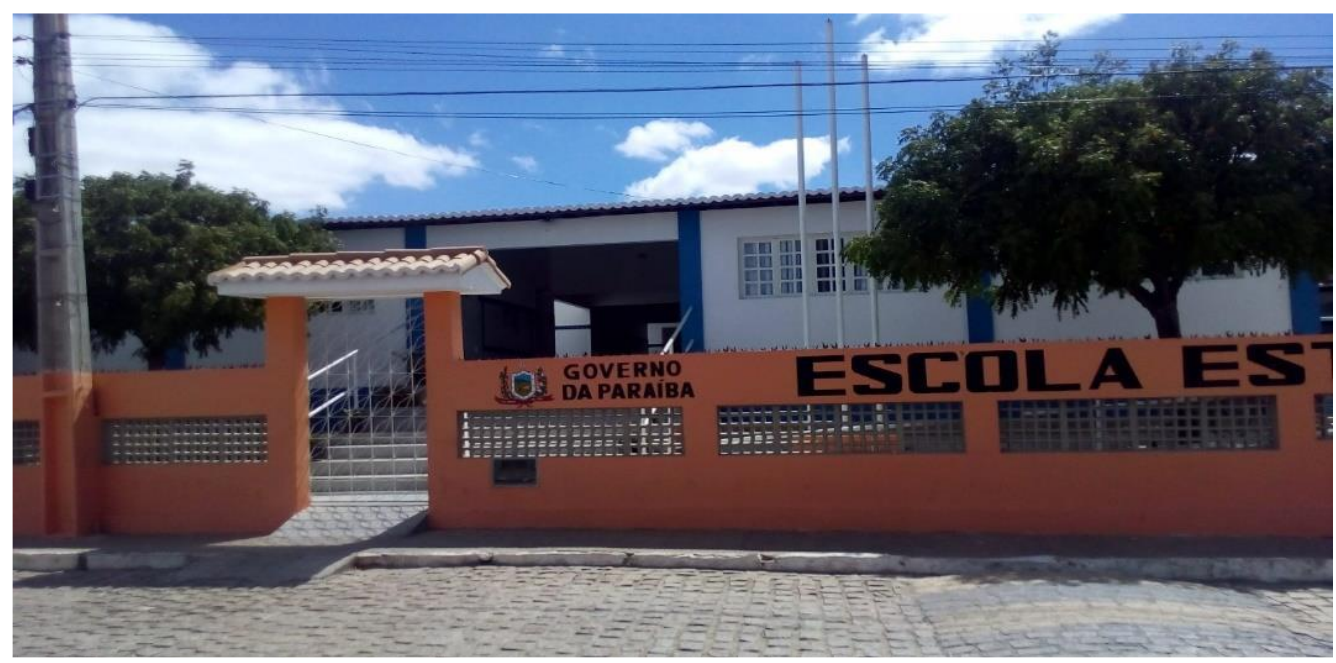

Figura1 - Vista frontal do prédio da Escola Estadual de Ensino Médio Prefeito Aguitônio Dantas, Frei Martinho - PB, 2017.

Fonte: Dados da pesquisa, 2017. 


\subsection{Procedimentos de coleta de dados e análise de dados}

Para a coleta de dados se fez o uso da aplicação de questionários (Figura 2) com caráter quali-quantitativo, que depois com a utilização de aplicativos se fez a análise dos resultados.

A metodologia adotada trata-se de um estudo de caso, onde, durante sua realização houve momentos de coleta de dados através da aplicação de questionários semiestruturados aos alunos no período inicial e no período final da pesquisa e aplicação de método de ensino diferenciado para cada turma estudada.

Foram realizadas aulas expositivas sobre classificação dos peixes, diversidade de espécies ornamentais, a prática da aquariofilia e o uso das tecnologias na educação, assim como, foram aplicadas abordagens de ensino diferenciadas, tais como, o uso da mídia, jogos didáticos, confecção de modelos didáticos e construção de Blog educativo todos referentes ao tema estudado, peixes ornamentais.

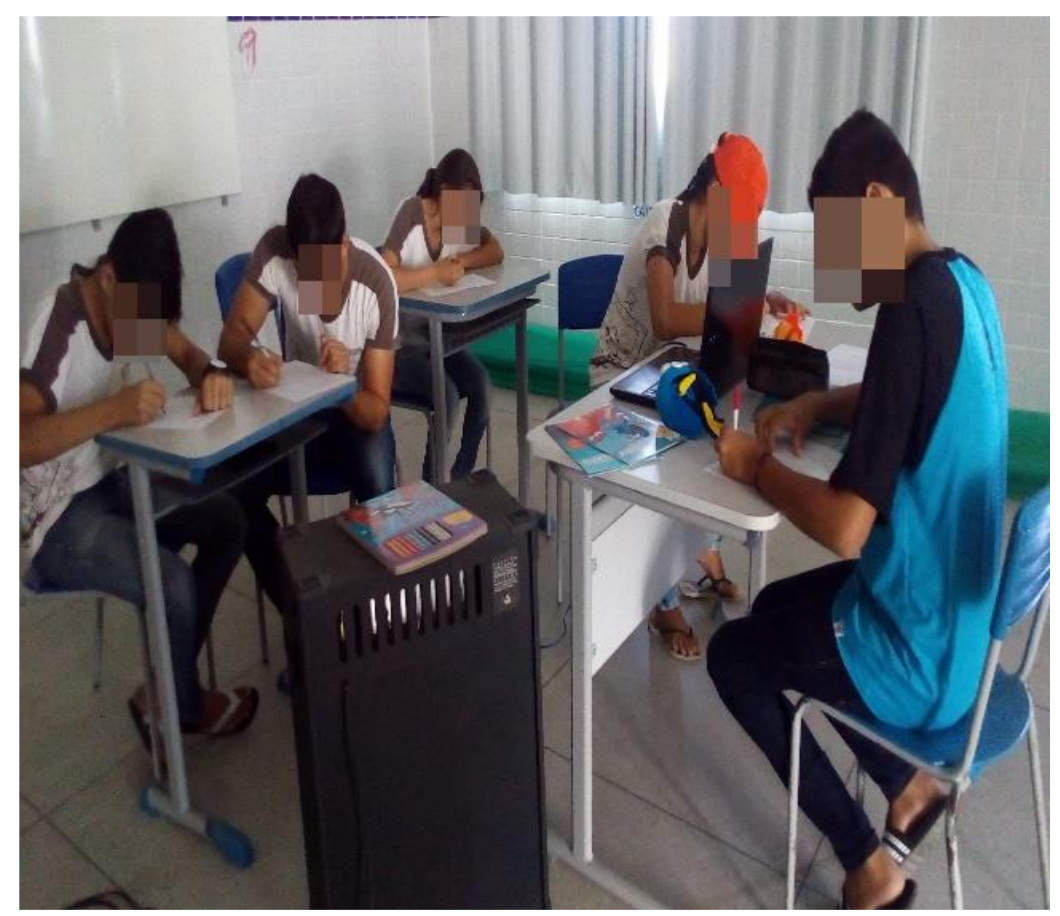

Figura 2 - Aplicação de questionário inicial para a diagnose dos alunos pesquisado na E.E.E.M Prefeito Aguitônio Dantas, 2017.

Fonte: Dados da pesquisa, 2017. 


\section{RESULTADOS E DISCUSSÃO}

Serão expostos a seguir, os resultados obtidos referentes à aplicação dos questionários de diagnose, desenvolvimento das atividades propostas e a avaliação final de cada método de ensino.

\subsection{Método de ensino 1: Aplicação de filme "Procurando Nemo" e jogos didáticos}

O questionário de diagnose aplicado em ambas as turmas, $1^{0}$ e $2^{0}$ ano, contemplava questões abertas onde os alunos eram interrogados a respeito de características referentes ao grupo dos peixes e quais as diferenciavam dos peixes ornamentais, se conheciam ou criavam alguma espécie, assim como, referente a prática de criá-los.

Foi possível observar que não houve diferenças nas respostas apresentadas nos questionários iniciais nas duas séries pesquisadas

A princípio foi possível observar que mais da metade dos entrevistados (72\%) apresentaram respostas satisfatórias ao serem questionados sobre que características diferem os peixes ornamentais das demais espécies de peixes, citando atributos como: cores, tamanhos e formas. Também foi possível observar que (14\%) dos estudantes não souberam responder ou não quiseram opinar (14\%), onde se percebeu através de uma análise mais detalhada que esse número variava entre as duas turmas $\left(1^{0} \mathrm{e} 2^{0} \mathrm{ano}\right)$.

Segundo Souza (2007), a utilização de recursos didáticos no processo de ensino-aprendizagem é imprescindível para que o aluno compreenda o conteúdo trabalhado, desenvolvendo sua criatividade, coordenação motora e habilidade ao manusear objetos diversos que poderão ser usados pelo professor na aplicação de suas aulas.

Reis (2015), em sua pesquisa com visita guiada de estudantes sobre as diferentes espécies de peixes e seus ecossistemas, tiveram a oportunidade de conhecer linhagens de peixes Betta splendens, entre outras, com isso favorecendo em seu aprendizado vendo na prática as características dos peixes e do ambiente em que eles vivem. 
Essas atividades poderiam ser mais implementadas, fazendo com que 0 estudante adquira conhecimentos fora da sala de aula e sintam mais atração pelo conteúdo.

Se referindo às espécies de peixes ornamentais que os alunos conhecem, foram citadas várias espécies, com destaque para o peixe palhaço e o peixe Betta. Esse fato se atribui, possivelmente, à exposição na mídia das espécies citadas, tornando-as mais populares e com isso sendo citadas com facilidade. Também foi possível observar que (33\%) dos estudantes disseram não conhecer. Outras espécies de peixes que não são consideradas ornamentais foram citadas, como a tilápia e a traíra, isso provavelmente por serem espécies mais populares da região em que vivem os estudantes.

Sendo assim, diante do exposto, pela análise dos questionários aplicados, é possível constatar que a maioria dos educandos apresenta apenas o conhecimento que está sendo repassado pela mídia, de forma superficial e distante da realidade, alguns percebem algumas espécies apenas como criadas pela mídia. Foi observado também, que o conhecimento que possuem se restringe à espécies de peixes que são mais comuns na região em que vivem e sendo utilizados principalmente como fonte de alimento.

Após a análise dos questionários, foi possível desenvolver as aulas expositivas, abordando aspectos referentes à classificação dos peixes de forma geral, morfologia, diversidade de peixes ornamentais, mostrando alguns exemplos, sua importância ecológica e econômica e a prática da aquariofilia nas escolas brasileiras. Os recursos utilizados para aplicação das aulas eram próprios da escola.

Pode-se perceber que alguns estudantes, trazem consigo algumas concepções, sobre aspectos morfológicos dos peixes formados pelo seu convívio social e cultural, porém de repassados de forma "errônea" ou pouco distorcidas, concepções construídas pelo senso comum para facilitar o diálogo e o dia-a-dia.

Após a realização das aulas expositivas, foi possível aplicar o primeiro método de ensino, o filme "Procurando Nemo", aos alunos do $1^{0}$ ano, e em seguida foi aplicado um jogo didático como quebra-cabeça, e a resolução de um periódico contendo variedade de jogos, onde ambos tratavam sobre o filme. 
Segundo Pedroso (2009) para de reverter os problemas que afligem a área de educação, acredita-se que a implementação de novas práticas educativas, dentre as quais se destaca o uso de estratégias de ensino diversificadas, possam auxiliar na superação dos obstáculos. Para Rosa (2000), toda ferramenta de Ensino, até mesmo o uso de um filme ou de uma simulação multimídia deve ter uma função definida no plano de Ensino elaborado pelo Professor para um dado conteúdo.

Ao final dessa atividade, foi aplicado com os 28 estudantes do $1^{0}$ ano, um questionário de diagnose das concepções adquiridas através do filme e de todas as atividades desenvolvidas durante o projeto foi realizada. Pode-se perceber que todos concordam que uso de novas metodologias, como mídias e jogos educativos, facilitam a aprendizagem, atraindo a atenção dos estudantes para 0 assunto trabalhando (Tabela 1).

Tabela1 - Síntese das questões abordadas no questionário final aplicado aos educandos de $1^{\circ}$ série do ensino médio da E.E.E.M Prefeito Aguitônio Dantas, Frei Martinho - PB.

\begin{tabular}{l|l|l|l|l}
\hline \multicolumn{1}{c|}{ Questão } & Sim & $\%$ & Não & $\%$ \\
\hline Já havia assistido ao filme? & 27 & 96,4 & 1 & 3,6 \\
\hline $\begin{array}{l}\text { Se já estudaram nas aulas de Biologia algum assunto que } \\
\text { aparece no filme? }\end{array}$ & 14 & 50 & 14 & 50 \\
\hline $\begin{array}{l}\text { Se o uso de filmes, desenhos e jogos didáticos poderiam } \\
\text { auxiliar na aprendizagem? }\end{array}$ & 28 & 100 & --- & --- \\
\hline
\end{tabular}

Fonte: Dados da Pesquisa

Para Pedroso (2009) as atividades lúdicas, em especial o jogo didático (JD), foco deste estudo, são uma alternativa viável e interessante para aprimorar as relações entre professor - aluno - conhecimento.

\subsection{Método de ensino 2: Confecção de modelos didáticos de aquário e peixes ornamentais}

Essa etapa foi desenvolvida com alunos do $2^{\circ}$ ano do ensino médio, perfazendo um total de 23 educandos. Os dados coletados a partir do questionário de diagnose das concepções prévias foram analisados e utilizados na realização dos procedimentos seguintes, que se constitui na elaboração de aulas expositivas sobre os peixes ornamentais, onde nessas, eram abordadas 
questões referentes à sistemática, morfologia, anatomia, diversidade de peixes ornamentais, importância econômica e ecológica, e prática da aquariofilia nas escolas.

Após a realização das aulas expositivas, que tiveram no $2^{\circ}$ ano como foco a prática da aquariofilia, o assunto que, segundo Pereira e Souza (1999), se trata de uma atividade presente em algumas escolas brasileiras. Diante disso, foi proposto que confeccionassem modelos representativos de algumas espécies de peixes ornamentais, tais como Peixe Dory (Paracanthurus hepatus) e Peixe Palhaço (Amphiprion frenatus), como também produzirem um ambiente de aquário com ouso materiais como: caixa de papelão, revistas, papel crepom, técnica papel machê, cola, tintas e etc. (Figura 3). Por fim, foi aplicado aos 23 estudantes envolvidos, um questionário de diagnose das concepções adquiridas, que após analisado, apresenta resultados satisfatórios.

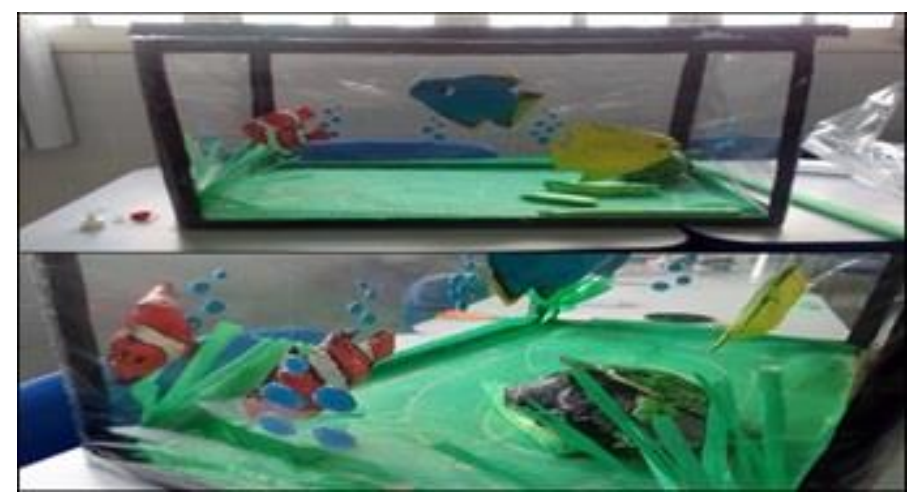

Figura 3 - Confecção de modelos didáticos. Fonte: Dados da pesquisa, 2017.

Fonte: Dados da pesquisa, 2017.

Diante do exposto, como demonstra a análise das respostas e observado durante as atividades, houve uma maior interação entre professor-aluno e aluno-conteúdo, quando são abordados conteúdos que são trabalhados de forma mais tradicionais utilizando novas metodologias, fazendo com que, os alunos possam enxergá-los fora do contexto sala de aula, no convívio social e como prática efetiva nas suas relações com o mundo. $E$ principalmente, enxergar os conteúdos trabalhados em sala como interessantes e de fundamental importância na sua formação crítico cidadã. 


\subsection{Método de ensino 3: construção de blog educativo para o ensino de Zoologia}

O desenvolvimento desse método se deu na turma do $3^{\circ}$ ano, onde foram aplicados questionários semiestruturados na turma, no intuito de identificar 0 perfil dos educandos no tocante dos assuntos que os mesmos costumavam pesquisar na Internet.

Posteriormente foram apresentadas aulas expositivas que falavam sobre a diversidade de peixes ornamentais, importância ecológica e econômica, assim como, o uso de blogs na educação. Em seguida foi construído e confeccionado um blog, no intuito de formar um espaço de debate e busca de conhecimento entre os alunos.

Para responder o questionário de diagnose os educandos apresentaram informações básicas acerca de informática, bem como informações sobre suas rotinas de acesso à internet, isso claro, para aqueles que dispunham do recurso.

Como visto na figura acima, a maioria dos alunos entrevistados (20) disseram acessar a internet em suas próprias casas, o que demonstra que este é um recurso atualmente presente na maioria das residências, fazendo parte da rotina de muitos. Outros disseram acessar a internet na casa de amigos (3) e apenas 1 (um) diz acessar na escola.

Foi observado as utilizações da internet mais empregadas pelos educandos, onde citaram o facebook (22), sites de pesquisa (5), e-mail (5) e outros, tais como, WhatsApp, Instagram e etc. (24). O que significa que os jovens estão sempre em busca de inovações tecnológicas que os mantenha conectados e interagindo entre eles e com o mundo.

Quando questionados sobre suas rotinas de acesso à internet, a maioria (79\%) dos entrevistados disseram não possuir computador com acesso à internet em casa, mas o que percebe é que, muitos dos jovens fazem uso de suas redes sociais através do aparelho celular. Sobre com que frequência costumam utilizar a internet (96\%) afirmaram todos os dias e sobre qual a principal finalidade ao utilizá-la (79\%) respondeu que para entretenimento. Porém, quando perguntados em que nível de informática se julgava enquadrar apenas (14\%) como médio e (10\%) como básico. 
Rosa (2000), relata que a possibilidade, antes oferecida pelo rádio e pela $\mathrm{TV}$, principalmente, e atualmente com maior enfoque pela Internet, que atinge um grande número de alunos, muitas vezes dispersos em grandes áreas geográficas, é um canto de sereia a perseguir os planejadores educacionais. Já Reis (2015), ressalta a importância dada por estes adolescentes à interação social, pelo uso da internet, mesmo que por meio da internet eles busquem diversão e lazer, constatou-se a formação de auto imagem, uma vez que eles expressam suas características pessoais, eles tem habilidades para usar outras ferramentas online. Como método de ensino trabalhado com a turma do $3^{0}$ ano, os blogs são uma ferramenta pouco utilizadas pelos estudantes entrevistados, apesar de (95\%) disserem já ter visitado um blog, apenas (4\%) disseram possuir um blog pessoal.

Após a aplicação do questionário inicial e tendo traçado o perfil dos estudantes envolvidos na pesquisa, pôde-se desenvolver as aulas expositivas e em seguida os alunos foram levados para o laboratório de informática da escola e orientados para montagem de um blog educativo, relacionado ao ensino de peixes ornamentais.

O blog montado recebeu o título de "BLOG ZOO PEIXES ORNAMENTAIS", nele continha informações sobre a diversidade de espécies e suas classificações, a prática da aquariofilia, metodologias aplicadas ao ensino de peixes ornamentais, como também conteúdos e imagens das aulas desenvolvidas durante o projeto (Figuras 4 e 5). 


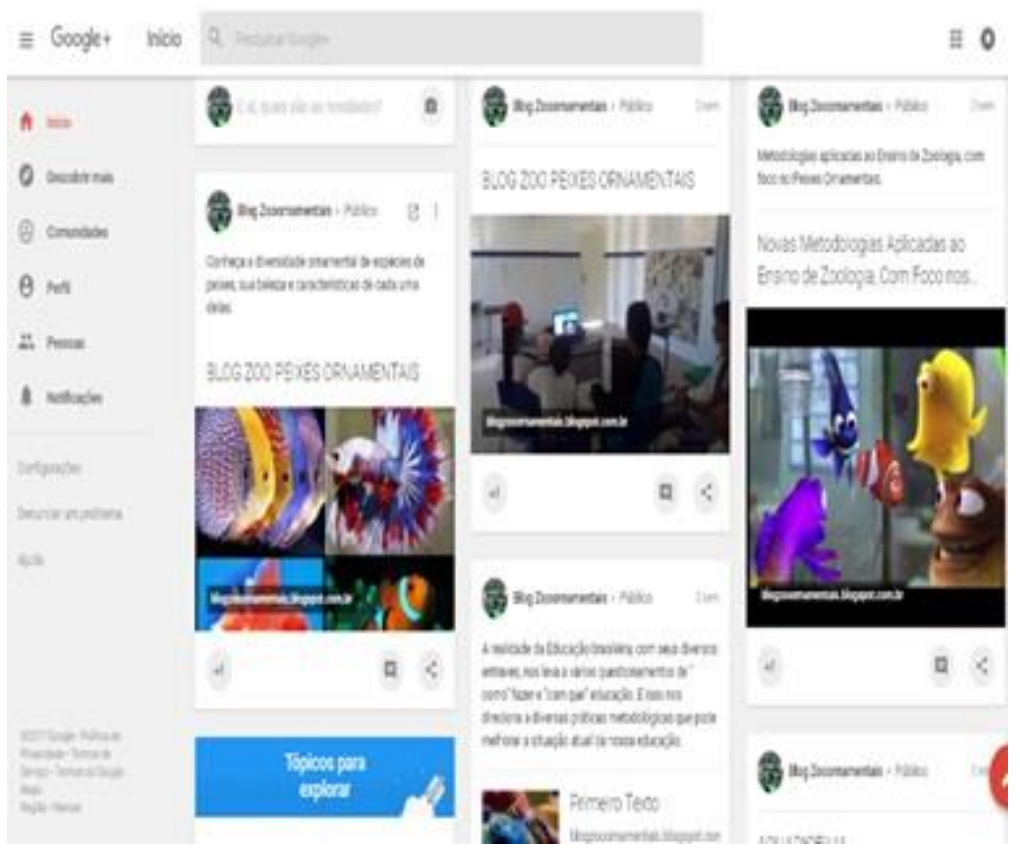

Figura 4 - Blog Zoo Peixes ornamentais elaborado pela turma do $3^{\circ}$ ano do ensino médio da E. E. E.M. Prefeito AguitônioDantas.Fonte: http://blogzooornamentais.blogpost.com

Fonte: Dados da pesquisa, 2017.

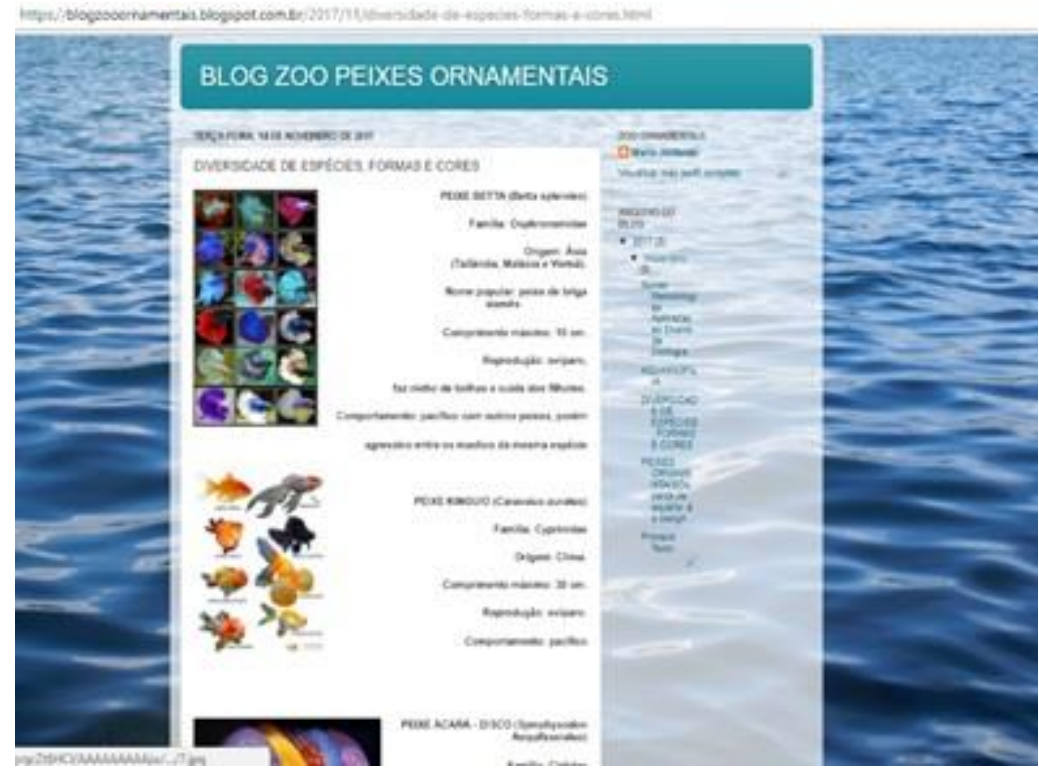

Figura 5 - Blog Zoo Peixes Ornamentais, atividades desenvolvidas durante o projeto na E. E. E. M. Prefeito AguitônioDantas.Fonte: http://blogzooornamentais.blogpost.com

Fonte: Dados da pesquisa, 2017

Através da aplicação e análise do questionário final, os alunos foram questionados sobre a importância de discutir temas relacionados ao ensino de Biologia nas redes sociais e todos (100\%) afirmaram que, esta metodologia pode sim facilitar a aprendizagem dos conteúdos. Fato comprovado, quando foram perguntados sobre a colaboração do blog e os novos conhecimentos 
trazidos por meio dele, todos foram unânimes (100\%) em afirmar a eficácia desse método.

Moratori (2003), ressalta que a introdução do computador na escola através do argumento de que este é um instrumento eficaz, pois possibilita o aumento da motivação dos alunos e cria atividades que constituem oportunidades especiais para aprender e resolver problemas.

A partir disso, foi observado então, durante as práticas de montagem e desenvolvimento do blog, assim como na análise dos questionários, tanto inicial como final, a aplicabilidade desse método, que promove além da interação entre professor-aluno e aluno-conteúdo a facilidade de compreensão dos conteúdos ensinados e aprendizagem de novos conhecimentos, através das buscas de informações que movimentam um blog.

\section{CONCLUSÕES}

O desenvolvimento dos métodos propostos pela presente pesquisa foi bem sucedido, e levou a uma série de colocações que acabam por evidenciar algumas das contribuições que podem ser fornecidas por eles na construção de uma aprendizagem mais efetiva da Zoologia.

A utilização de questionários demonstrou ser uma ferramenta importante para o desenvolvimento das atividades, pois permitiram conhecer um pouco o perfil dos entrevistados, para que se pudesse desenvolver as atividades, e também ter a noção de como tratar o tema do estudo de acordo com os conhecimentos trazidos pelos alunos à escola e suas perspectivas em relação ao assunto trabalhado/desenvolvido.

O uso do filme "Procurando Nemo" e de jogos didáticos facilitou aos estudantes notar a presença de uma infinidade de espécies e conceitos biológicos como: biodiversidade, relações ecológicas entre espécies, impactos ambientais causados por ações antrópicas e a retirada de espécies de seu habitat natural. $E$ isso ficou demonstrado nas respostas dos questionários, onde apresentaram maior facilidade em discorrer sobre tais assuntos e conceitos.

Em relação ao uso dos modelos didáticos nas aulas de Biologia, estes se configuram como recursos didáticos que estimulam a participação dos 
estudantes na aula e também a aproximação entre o professor e a turma. Estes recursos envolvem os alunos na busca por desenvolverem um modelo didático e facilitam a assimilação e aprendizagem de alguns termos e nomenclaturas. Além de promover aos estudantes, através de características lúdicas, um aprendizado mais facilitado de certos conteúdos, vistos por eles como difíceis e sem importância na sua formação, tornam o processo de ensino-aprendizagem mais efetivo durante a aplicação dos modelos.

Sobre o uso do blog como mediador da aprendizagem, foi possível perceber que essa ferramenta importante, se bem aplicada e utilizada proporciona maior interatividade nas aulas, atraindo a atenção dos alunos para o ensino, tornando-a mais prazerosa.

O envolvimento dos educandos em práticas educativas que fujam da rotina sala de aula, quadro e giz, proporciona aos mesmos ampliar sua visão em relação ao ensino das disciplinas, percebendo sua abordagem sendo contextualizada, além exprimir sua criatividade e criticidade em relação aos temas, metodologias que são tratados em sala.

Essa prática ainda faz com que ocorra uma aproximação entre professoraluno e aluno-aluno, no compromisso de desenvolver um bom projeto, uma boa prática que envolva a confecção de modelos didáticos e outros, estreitando assim, relações que servirão na melhoria do processo ensino-aprendizagem. Observou-se que ocorreu de acordo com as opiniões apresentadas pelos estudantes, uma maior aprendizagem dos assuntos relacionados à Zoologia, com ênfase no tema abordado na pesquisa.

\section{REFERÊNCIAS}

BIZZO, Nelio. Ciências: fácil ou difícil? Coleção Palavras de professor. 2. ed. São Paulo: Editora Ática, 2008.

COSTA, Paula Gabriela da; RIVA, Poliana Barbosa da; OBARA, Ana Tiyomi; SUZUKI, Harumi Irene; TAKEMOTO, Ricardo Massato. Saberes etnoecológicos dos pescadores artesanais e alunos da planície alagável do alto rio Paraná. Revista Eletrônica do Mestrado em Educação Ambiental, Rio Grande, RS, v. Especial, p. 86-96, maio, 2014. 
HOLMESLAND, Içara da Silva. Qualidade e equidade no acesso ao conhecimento: experiência de uma sociedade igualitária. Educação, n. 50, p. 47-70, 2003.

LIMA, Kênio Erithon Cavalcante. VASCONCELOS, Simão Dias. Análise da metodologia de ensino de ciências nas escolas da rede municipal de Recife. Ensaio: aval. Pol. Públi. Educ. v. 14, n. 52, p 397-412, 2006.

MORATORI, Patrick Barbosa. POR QUE UTILIZAR JOGOS EDUCATIVOS NO PROCESSO DE ENSINO APRENDIZAGEM ?. UNIVERSIDADE FEDERALDO RIO DE JANEIRO. INSTITUTO DE MATEMÁTICA. RIO DE JANEIRO, RJ - BRASIL Dezembro, 2003. Disponivel em: < http://www.nce.ufri.br/GINAPE/publicacoes/trabalhos/t 2003/t 2003 patrick barbosa moratori.pdf>. Acesso em 16 de Agosto de 2019.

NASCIMENTO, Lucy Mirian Campos Tavares. Blogs e outras redes sociais no ensino de Biologia: o aluno como produtor e divulgador. Mestrado Profissional em Ensino de Ciências (Programa de Pós-graduação em Ensino de Ciências). Universidade de Brasília, Brasília - DF, 2012.

PEDROSO, Carla Vargas. JOGOS DIDÁTICOS NO ENSINO DE BIOLOGIA: UMA PROPOSTA METODOLÓGICA BASEADA EM MÓDULO DIDÁTICO. IX Congresso nacional de Educação - EDCUCERE. 2009. Disponivel em: < https://educere.bruc.com.br/arquivo/pdf2009/2944 1408.pdf>. Acesso em 15 de Agosto de 2019.

PEREIRA, Júlio Emílio Diniz. As licenciaturas e as novas políticas educacionais para a formação docente. Revista Educação \& Sociedade. Ano XX, n. 68, Dezembro, 1999, pp.109-125.

REIS, Paulo Cesar Nepomuceno dos. SEIXAS FILHO, José Teixeira de. MELLO, Silvia Conceição Reis Pereira. AQUARIOFILIA COMO FERRAMENTA DE EDUCAÇÃO AMBIENTAL NO ENSINO BÁSICO. Semioses, Rio de Janeiro. v. 9, n. 1 p. 43-57, jan./jun. 2015.2 Disponivel em: $<$ http://apl.unisuam.edu.br/revistas/index.php/Semioses/article/view/1981996X.2015v9

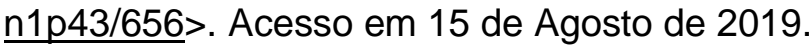


ROCHA, Danilo Luiz da. A utilização do aquário como ferramenta de aprendizagem interdisciplinar no ensino de ciências. Monografia de Especialização, Universidade Tecnológica Federal do Paraná, 2014.

ROSA, Paulo Ricardo da Silva. O USO DOS RECURSOS AUDIOVISUAIS E O ENSINO DE CIÊNCIAS. Cad.Cat.Ens.Fís., v. 17, n. 1: p. 33-49, abr. Campo GrandeMS, 2000.

Disponivel em: https://periodicos.ufsc.br/index.php/fisica/article/viewFile/6784/6249>. Acesso em 15 de Agosto de 2019.

SANTOS, Saulo Cesar Seiffert. Diagnóstico e possibilidades para o ensino de zoologia em Manaus/AM. 237 f. Dissertação (Mestrado Profissional em Educação e Ensino de Ciências na Amazônia). Universidade do Estado do Amazonas. Manaus/AM., 2010.

SERAFIM, Maria Lucia. SOUZA, Robson Pequeno de. Multimídia na educação: o vídeo digital integrado ao contexto escolar, p. 17-48. In. Tecnologias digitais na educação. Orgs. SOUZA, R. P.; MOITA, F. M. C. S. e CARVALHO, A. B. G. Campina Grande - PB, EDUEPB, 2011.

SOUZA, Salete Eduardo de. 0 uso de recursos didáticos no ensino escolar. Arq Mudi. 2007. Disponivel em: < http://www.dma.ufv.br/downloads/MAT\%20103/2015II/slides/Rec\%20Didaticos\%20-\%20MAT\%20103\%20-\%202015-II.pdf>. Acesso em: 15 de Agosto de 2019. 